\title{
ANÁLISE DO POTENCIAL DE DEGRADAÇÃO AMBIENTALNA BACIA HIDROGRÁFICA DO RIO PEQUENO EM SÃO JOSÉ DOS PINHAIS/PR, POR MEIO DO DFC - DIAGNÓSTICO FÍSICO CONSERVACIONISTA ${ }^{1}$ \\ Analysis of the potential ambient degradation and in the Hydrographic Basin of Pequeno River in São José dos Pinhais/PR, by the PCD - Physical Conservationist Diagnosis
}

\author{
Anderson Mendes $\mathrm{CHUEH}^{2}$ \\ Leonardo José Cordeiro SANTOS ${ }^{3}$
}

\section{RESUMO}

O objetivo deste artigo é aplicar a metodologia do Diagnóstico Físico-Conservacionista (DFC), e a partir desta metodologia e de algumas adaptações demonstrar os resultados obtidos na análise do potencial de degradação dos recursos naturais da bacia hidrográfica do rio Pequeno. A área de estudo localiza-se em São José dos Pinhais/PR, sendo que esta bacia encontra-se no limite da expansão da RMC - Região Metropolitana de Curitiba - e experimenta intenso conflito entre as possibili-dades e necessidades de ocupação e uso do solo.

\section{Palavras-chave:}

Bacia hidrográfica, uso do solo, degradação, recursos naturais.

\begin{abstract}
This article aims at applying the methodology of PhysicalConservationist Diagnosis (FCD), and from this methodology and from some adaptations we want to demonstrate the results obtained in the quantitative analysis of the potential of degradation of natural resources from the hydrographic basin of "Rio Pequeno" (Pequeno River). The area of the study is located in São José dos Pinhais/PR; this basin is located in the border of the expansion from Metropolitan Area of Curitiba (MAC) - and has the conflict between the possibilities and the occupation needs and soil use.
\end{abstract}

\section{Key-words:}

Hydrographic basin, use of the soil, degradation, natural resources.

\footnotetext{
${ }^{1}$ Este artigo é parte integrante de Dissertação de Mestrado apresentada ao curso de Pós-Graduação do Departamento de Geografia da Universidade Federal do Paraná em 2004.

${ }^{2}$ Mestre em Geografia, UFPR - andersonchueh@yahoo.com.br

${ }^{3}$ Professor Doutor do Departamento de Geografia da UFPR - santos@ufpr.br
} 


\section{INTRODUÇÃO}

O uso do solo está relacionado diretamente à degradação do ambiente pelas ações antrópicas, tanto diretas quanto indiretas. Estas ações podem variar em grau de intensidade conforme a função que um determinado ambiente assume, decorrente da apropriação dos seus recursos naturais, normalmente priorizando-se o fator socioeconômico em detrimento do ambiente físico, transformando-o em um espaço que demanda a sua exploração econômica, estabelecendo uma nova dinâmica na relação homem/natureza e gerando conseqüências no meio natural.

Este processo de apropriação e exploração ambiental carece de diagnósticos que contemplem as necessidades de se prevenir impactos ambientais considerados negativos, tanto para se evitar a degradação dos ambientes a serem explorados, quanto para minimizar as degradações já ocorridas, proporcionando subsídios técnicos no planejamento das ações mitigadoras.

Tendo como base esta necessidade, e buscando estabelecer parâmetros na exploração destes recursos, com especial atenção ao solo e à água, focaliza estudos sistêmicos que possibilitem um diagnóstico ambiental integrado do meio físico, pois só desta maneira adquirirse-á um instrumento adequado, tanto para o entendimento quanto à manutenção do equilíbrio ambiental.

Sob esta perspectiva, a área do presente estudo é a bacia hidrográfica do rio Pequeno, localizada no Município de São José dos Pinhais, entre as coordenadas $25^{\circ} 27^{\prime}$ e $25^{\circ} 37^{\prime}$ de latitude sul e os meridianos $48^{\circ} 58^{\prime}$ e $49^{\circ} 12^{\prime}$ de longitude oeste (Figura 1). A escolha desta bacia justifica-se pelo fato de que a mesma encontra-se no limite da expansão da RMC Região Metropolitana de Curitiba, e experimenta intenso conflito entre as possibilidades e necessidades de uso e ocupação do solo e as de manterem-se preservados seus recursos naturais, principalmente os hídricos, para que num futuro próximo sirva de fonte para o abastecimento de água à população.

Desta forma, o objetivo principal deste trabalho é buscar quantificar a degradação dos recursos naturais da bacia hidrográfica do rio Pequeno. Para isto, buscouse, como instrumento de análise da degradação dos recursos naturais e do ambiente como um todo, apoio na metodologia proposta por Beltrame (1994), adaptada do Centro Interamericano de Desenvolvimento de Águas e Terras (CIDIAT), com sede na Venezuela, e pelo Ministério do Ambiente e dos Recursos Naturais Renováveis (MARNR) também deste País, cuja denominação é Diagnóstico Físico Conservacionista
(DFC) que, segundo esta autora, se propõe a diagnosticar a situação real em que se encontram os recursos naturais renováveis e determinar o potencial de degradação destes recursos em um dado espaço geográfico, visando principalmente à manutenção dos recursos hídricos, solo e vegetação.

Em uma breve síntese, cabe ressaltar que a bacia do rio Pequeno já foi palco de diversos estudos. Dentre estes, têm-se:

Rocha (1996), que analisou o potencial de exploração das águas subterrâneas desta bacia hidrográfica, considerando as características hidrogeológicas e geoquímicas dos depósitos aluvionares existentes. De maneira geral, o estudo revelou que apesar da degradação ambiental presente ocasionada pela extração de material arenoso, originando cavas e limitando a exploração das águas subterrâneas, as cavas, por suas características hidrogeológicas e geoquímicas, podem servir como reservatório de água complementar ao abastecimento público da cidade de Curitiba.

Chueh (2000), abordando o uso e ocupação do solo sob a ótica da legislação ambiental nas Áreas de Preservação Permanente, baseando-se nos Arts. $2^{\circ} \mathrm{e}$ $10^{\circ}$ da Lei n. 4.771/65 - Código Florestal Brasileiro. O autor fez uma análise integrada, por meio de mapas e tabelas, entre as APPs - Áreas de Preservação Permanentes determinadas pela lei e o uso e ocupação efetivo do solo, pois este elevado grau de áreas de preservação não reflete a preocupação de preservação ambiental ou uma consciência adequada no cumprimento das normas ambientais legais. Mas, reproduz a condição geral da bacia, a qual pode ser explicada por diversos fatores, que não são os legais. Por exemplo, com a hipótese da funcionalidade da área em que está inserida a bacia hidrográfica, onde, no contexto socioeconômico, não era expressiva a exploração do ambiente natural em suas mais diversas formas. Entretanto, com a saturação das áreas próximas, passíveis então de serem exploradas, esta bacia assume uma nova função no desenvolvimento da configuração espacial da RMC, sentindo os efeitos das alterações decorrentes das ações antrópicas desordenadas.

Guimarães (2000) teve por objetivo determinar a magnitude das mudanças ocorridas no regime hidrológico, principalmente sobre a vazão do rio principal, o balanço hídrico e seus componentes num período de tempo entre 1952 e 1997 na bacia hidrográfica do rio Pequeno. A análise identificou as principais alterações de uso do solo, as quais foram mapeadas e que poderiam estar relacionadas a um possível incremento nas vazões máximas do rio Pequeno e determinadas por meio de análises temporais de vazão e precipitações, sendo que estas correlações foram apoiadas em dados estatísticos. 
CHUEH, A. M.; SANTOS, L. J. C. Análise do potencial de degradação ambiental na bacia...

FIGURA 1: LOCALIZAÇÃO GEOGRÁFICA DA ÁREA DE ESTUDO - BACIA DO RIO PEQUENO

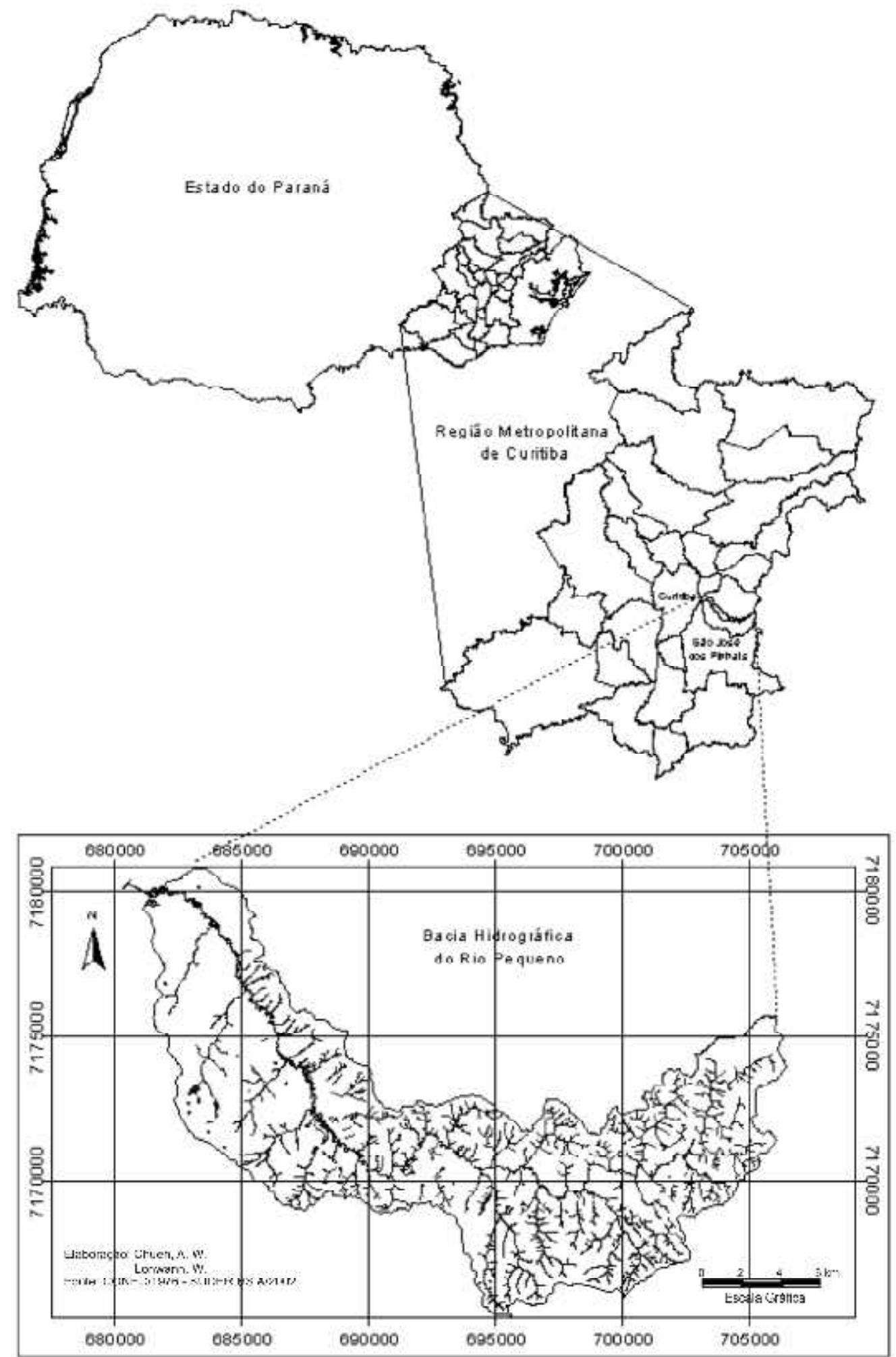


Boiko (2000), que aplicou a metodologia da análise de fragilidade ambiental por meio da determinação da fragilidade potencial, proposta por Ross (1991). A autora elaborou um mapeamento preliminar da fragilidade potencial e emergente nesta bacia, integrando a análise dos elementos do meio físico e das ações antrópicas, fornecendo subsídios ao ordenamento territorial e ao manejo dos recursos naturais.

Santos (2001), que apresentou alternativas para subsidiar o zoneamento e o planejamento ambiental baseado na modelagem de alguns processos geobiohidrológicos na bacia hidrográfica do rio Pequeno. Para tanto, foram empregados dois modelos distribuídos de base física, um hidrológico e outro geomorfológico. A partir destes dois modelos foram gerados mapas das áreas saturadas e dos processos erosivos, que foram analisados considerando o uso do solo e as áreas de preservação permanente de mata ciliar.

Santos (2002) buscou demonstrar a perda de solo por erosão hídrica na bacia do rio Pequeno, considerando as características do meio físico (clima, relevo, tipos de solos), associada ao uso e ocupação do solo e das práticas conservacionistas desta área. Para isto, foi aplicado o método USLE (Equação Universal de Perdas de Solo), que é um modelo matemático que possibilita quantificar a perda de solo por erosão hídrica.

Amaral (2002) analisou a relação entre o uso e ocupação do solo e a qualidade da água na bacia hidrográfica do rio Pequeno. Sob a ótica da análise sistêmica e apoiada em técnicas computacionais de geoprocessamento, a autora considerou os tipos de poluição que afetam os rios desta bacia, relacionando-os com os tipos de uso - ocupação do solo (espacial) em uma análise socioespacial evolutiva (temporal) e suas interferências na qualidade da água. Segundo a autora, houve grandes alterações no uso - ocupação do solo ao longo de sua análise têmporo-espacial, com alteração da atividade predominante que era a agrícola, a qual somada a outras atividades tem refletido na qualidade da água da bacia.

A síntese destas pesquisas mostra que os enfoques ou resultados foram apoiados, normalmente, em alguns parâmetros específicos. Portanto, a contribuição que se deseja nesta pesquisa é aproveitar os estudos já realizados e agregá-los em uma metodologia que contemple todos os parâmetros estudados separadamente.

\section{ASPECTOS FísICOS NATURAIS DA ÁREA DE ESTUDO}

A bacia hidrográfica do rio Pequeno está localizada na região natural do Primeiro Planalto
Paranaense, apresenta uma área de drenagem em torno de $130 \mathrm{~km}^{2}$, o seu rio principal é afluente da margem esquerda do rio Iguaçu, localizado no alto curso da bacia hidrográfica homônima - a maior do Estado do Paraná. Seus afluentes menores são os rios Purgatório e Charqueado, cujas nascentes aparecem junto à Serra do Mar e o rio Pequeno desenvolve-se em direção ao rio Iguaçu no sentido leste - oeste, sua maior parte está situada na Bacia Sedimentar de Curitiba, tem como limites: ao norte a bacia do rio Itaqui, ao sul a bacia do rio Miringuava, a leste o relevo montanhoso da Serra do Mar e a oeste o rio Iguaçu.

Esta bacia é composta por duas unidades geológicas: o Complexo Granítico da Serra do Mar ou Complexo Cristalino que ocorre nas porções central e nordeste da bacia (ROCHA, 1996), e a bacia sedimentar de Curitiba, que é formada sobre rochas metamórficas e plutônicas originadas no Pré-cambriano, recobertas com sedimentos do período Quaternário e rochas do Mesozóico. Deste contexto geológico mais amplo, foram apontados cinco grupos geológicos, sendo: Aluviões atuais e Terraços aluvionares; Formação Guabirotuba; Complexo Gnáissico-Migmatíticos e Complexo Granítico-Gnáissico (MINEROPAR, 1994/SUDERHSA, 2002).

A geomorfologia é representada pelas vertentes curtas e vales em forma de "V", com relevo montanhoso nas áreas de maiores altitudes localizadas no alto curso da bacia, são as áreas de maior declividade, normalmente superiores a $45^{\circ}$ e com altitudes acima de 1.000 metros, principalmente nas encostas oeste da Serra do Mar, onde estão as nascentes dos afluentes do rio Pequeno, os rios Charqueado e Purgatório.

A parte central possui relevo mais suave, com amplas colinas arredondadas em forma de meia laranja, declividade mais branda e presença de depósitos aluvionares mais significativos em relação ao alto curso da bacia (GUIMARÃES, 2000).

No terço inferior, é caracterizada a sudoeste pelas várzeas de inundação do rio Pequeno, por vertentes longas e de baixa declividade. A formação Guabirotuba aflora na forma de colinas suavemente arredondadas e limita a planície de inundação do rio Pequeno com terraços fluviais aplainados, amplos interflúvios e depósitos aluvionares influenciados pela confluência com o rio.

Os solos verificados na bacia do rio Pequeno foram: Cambissolo, Latossolo e Argissolo Vermelhoamarelo, Gleissolos e Organossolos; suas características morfológicas são fatores condicionantes importantes a serem considerados na análise integrada de um ambiente, pois a convenção que estabelece o uso e/ou parcelamento da terra, além de outras, está 
relacionada com a gênese e a formação dos solos, o que permitirá estabelecer parâmetros para limitar ou não os seus diferentes usos.

A cobertura vegetal desta bacia hidrográfica, ao longo do tempo, tem apresentado variações da sua formação original. Nas margens do rio Pequeno e afluentes ocorre a formação Floresta Ombrófila Mista Aluvial, também conhecida como mata de galeria, ciliar ou ripária. Ocupa as áreas da formação geológica dos Aluviões atuais, podendo ser vista ao longo dos cursos de água que formam vales sujeitos a inundações periódicas, em todo baixo curso e no médio curso nos fundos de vales planos, esta formação se intercala com as várzeas ou Formações Pioneiras com influência Fluvial (herbácea/arbustiva), que ocorrem nas áreas permanentemente alagadas, que funcionam como reguladoras do fluxo das águas dos rios para as terras contíguas no período das cheias.

As formações de maior porte predominam nas encostas que limitam a Serra do Mar no alto curso da bacia até o médio curso e são representadas pelas Florestas Ombrófilas Densa Montana e Mista Montana. Entretanto, nas porções mais elevadas com altitude média acima de $1.200 \mathrm{~m}$ s. $\mathrm{n}$. m., pode ser encontrada a Floresta Ombrófila Densa Altomontana que apresenta associações arbóreas simplificadas e de porte reduzido, regido por condicionantes climáticas e pedológicas mais restritas ao desenvolvimento das árvores (RODERJAN et al., 2002).

Entrando nos domínios do baixo curso da bacia, a cobertura vegetal toma outra feição, pois originalmente onde predominavam os Campos, com relevo suaveondulado, há a ocupação pelo uso agrícola e da pecuária, entre outros.

\section{APRESENTAÇÃO DO DIAGNÓSTICO FÍSICO- CONSERVACIONISTA - DFC}

O diagnóstico físico-conservacionista - DFC tem como objetivo determinar o potencial de degradação ambiental de uma bacia hidrográfica. Para isto, segundo Beltrame (1994), são estabelecidos indicadores potenciais de proteção ou degradação dos recursos naturais renováveis da bacia escolhida. Os parâmetros são selecionados devido a sua capacidade potencial intrínseca de contribuírem para a degradação dos recursos naturais renováveis ou refletirem essa degradação. Estes parâmetros expressos numericamente, por meio de uma fórmula descritiva, resultam no índice de risco de degradação física da bacia hidrográfica. Para cada parâmetro encontrado, definiu-se um índice de classificação previamente estabelecido.
Desta forma, consideraram-se quatro grandes fatores potenciais naturais de degradação física e, a partir deles, são definidos sete parâmetros componentes da fórmula descritiva do estado físico conservacionista da bacia. São eles:

I - Vegetação - considerada sob dois aspectos:

a) pelo grau de semelhança entre a cobertura vegetal atual e a cobertura vegetal original dos setores da bacia (CO);

b) pelo grau de proteção da cobertura vegetal fornecido ao solo (CA).

II - Clima - considerado:

a) pela erosividade da chuva (E);

b) pelo balanço hídrico da bacia $(\mathrm{BH})$.

III - Características geológicas e pedológicas - sob dois aspectos:

a) pela suscetibilidade da textura à erosão, associada à declividade (PE);

b) pela densidade de drenagem (DD).

IV - Características do relevo - considerado em termos de declividade média (parâmetro DM).

Esta proposta metodológica está embasada teoricamente em trabalhos desenvolvidos pelo Centro Interamericano de Desenvolvimento de Águas e Terras (CIDIAT) com sede na Venezuela, e pelo Ministério do Ambiente e dos Recursos Naturais Renováveis (MARNR) deste mesmo país. De acordo com Beltrame (1994), esta metodologia é mais ampla, abrangendo não apenas o Diagnóstico Físico Conservacionista, mas um conjunto de vários outros diagnósticos (socioeconômico, água, fauna, solo, etc.) que se interrelacionam, compondo o DIBH (Diagnóstico Integral da Bacia Hidrográfica).

A metodologia do DFC é um diagnóstico preliminar, necessário para o embasamento de todos os demais. Mesmo sendo genérico, é abrangente e prático na obtenção de valores objetivos que avaliem o estado físico conservacionista de uma bacia hidrográfica, de modo que serviu de base à análise da degradação física do ambiente na bacia do rio Pequeno, em que foram feitas algumas adaptações na obtenção de alguns índices dos parâmetros, conforme exposição no Quadro 1.

Na aplicação do DFC, a bacia hidrográfica é subdividida em setores menores, e este procedimento metodológico visa ao planejamento integral da mesma. Segundo Beltrame (1990), estas unidades de planejamento deverão seguir critérios hidrológicos, ou seja, a delimitação se fará de acordo com a linha do 
CHUEH, A. M.; SANTOS, L. J. C. Análise do potencial de degradação ambiental na bacia...

QUADRO 1: ADAPTAÇÕES NA METODOLOGIA DO DFC, PROPOSTA POR BELTRAME (1990).

\begin{tabular}{|c|c|}
\hline $\begin{array}{c}\text { METODOLOGIA PROPOSTA POR BELTRAME } \\
(1990):\end{array}$ & ADAPTAÇOES FEITAS \\
\hline $\begin{array}{c}\text { Cobertura Vegetal Original (Co), por descriçöes } \\
\text { de Klein (1960, } 197 \mathrm{a} \text { a 1980) }\end{array}$ & $\begin{array}{c}\text { Cobertura Vegetal Original (Co), por descriçöes de } \\
\text { publicaçes cientficas, a levantamentos } \\
\text { fitogeogrăicos de órgāos governamentais }\end{array}$ \\
\hline $\begin{array}{c}\text { Cobortura Vegotal Atual (CA): por imag̣ens do } \\
\text { satélites LANDSAT-TM }\end{array}$ & $\begin{array}{c}\text { Uso do salo atual por imagem de satélite } \\
\text { LANDSAT-ETM-7+, considerando áreas urbanas }\end{array}$ \\
\hline $\begin{array}{l}\text { Erosividade da Chuva (E) por equaçōos do } \\
\text { Lombardi \& Moldenhauer (1980) }\end{array}$ & $\begin{array}{l}\text { Erosividado ca Chuva (E) por cquaçào } \\
\text { desenvolvida por Rufino et al. (1993) }\end{array}$ \\
\hline Declividade Média (DM) & Dreclividade Média (DM) \\
\hline $\begin{array}{c}\text { Potencial Erosivo do Solo (PE), por associacáo da } \\
\text { suscetibilidade da textura do solo à erosăo e } \\
\text { declividade }\end{array}$ & $\begin{array}{c}\text { Potencial Erosivo do Solo (PE), pelas } \\
\text { caracteristicas morfológicas e comportamento } \\
\text { geral dos solos, associadas a suscelibilidade à } \\
\text { crosiào o doclividado }\end{array}$ \\
\hline Balanco Hídrico & $\begin{array}{l}\text { Balanco Hidrico, com base nos cáloulds das } \\
\text { normais de estaçóes metereológ cas e índices de } \\
\text { precipitação de período disponivel }\end{array}$ \\
\hline De & Densidade de Drenager ( $\mathrm{CD})$ \\
\hline
\end{tabular}

divisor de águas, setorizando assim a bacia em subbacias e/ou microbacias.

A fórmula descritiva utilizada foi a seguinte:

Onde:

$$
\mathbf{E}(\mathbf{f})=\text { COa CAb DMc Ed PEe DDf BHg }
$$

$\mathbf{E}(\mathbf{f})$ - estado físico ambiental do setor que é proporcional aos parâmetros:

COa - cobertura vegetal original: define o tipo de vegetação que deveria existir originalmente, de acordo com determinadas condições de edáficas e/ou fitogeográficas. Busca-se o grau de semelhança entre a cobertura vegetal original e a cobertura atual (a é o índice específico);

CAb - cobertura vegetal atual: define o grau de proteção do solo proporcionado pelo tipo de cobertura existente (b é o índice específico);

DMc - declividade média: este parâmetro é utilizado para caracterizar o relevo dos setores de uma bacia hidrográfica (c é o índice específico);

Ed - erosividade da chuva: corresponde à quantidade de solo que se perde pela erosão causada pelas chuvas (d é o índice específico);

PEe - potencial erosivo do solo: é a erodibilidade dos solos, ou seja, a suscetibilidade que apresentam de erodirem em diferentes taxas, devido às diferenças em suas propriedades e seus diversos usos (e é o índice específico);

DDf - densidade de drenagem: é o potencial da bacia e de seus setores em permitir maior ou menor escoamento superficial da água ( $f$ é o índice específico);

BHg - balanço hídrico: é a relação da entrada e saída de água no solo. Desequilíbrios no balanço hídrico poderão causar danos irreversíveis sobre os recursos naturais renováveis da área de estudo (g é o índice específico).

\section{RESULTADOS E DISCUSSÕES}

\section{SETORIZAÇÃO DA BACIA HIDROGRÁFICA DO RIO PEQUENO}

Para a setorização da bacia hidrográfica do rio Pequeno apresentada na Figura 2, utilizaram-se os critérios hidrográficos, a hipsometria, a declividade e também a elaboração do perfil longitudinal do rio Pequeno, o qual permitiu a identificação das alterações significativas na declividade do leito do rio principal.

Foram definidos três setores, o setor A corresponde à parte mais alta da bacia, abrangendo as nascentes do rio Pequeno, com altitudes variando em torno de $1.260 \mathrm{~m}$ nas cabeceiras dos rios Purgatório e $1.080 \mathrm{~m}$ no Charqueado, descendo aproximadamente até a cota de $900 \mathrm{~m}$, que é a linha divisória entre os setores $A$ e $B$ que representa a menor altitude deste setor. 
FIGURA 2: MAPA DOS SETORES DA BACIA HIDROGRÁFICA DO RIO PEQUENO

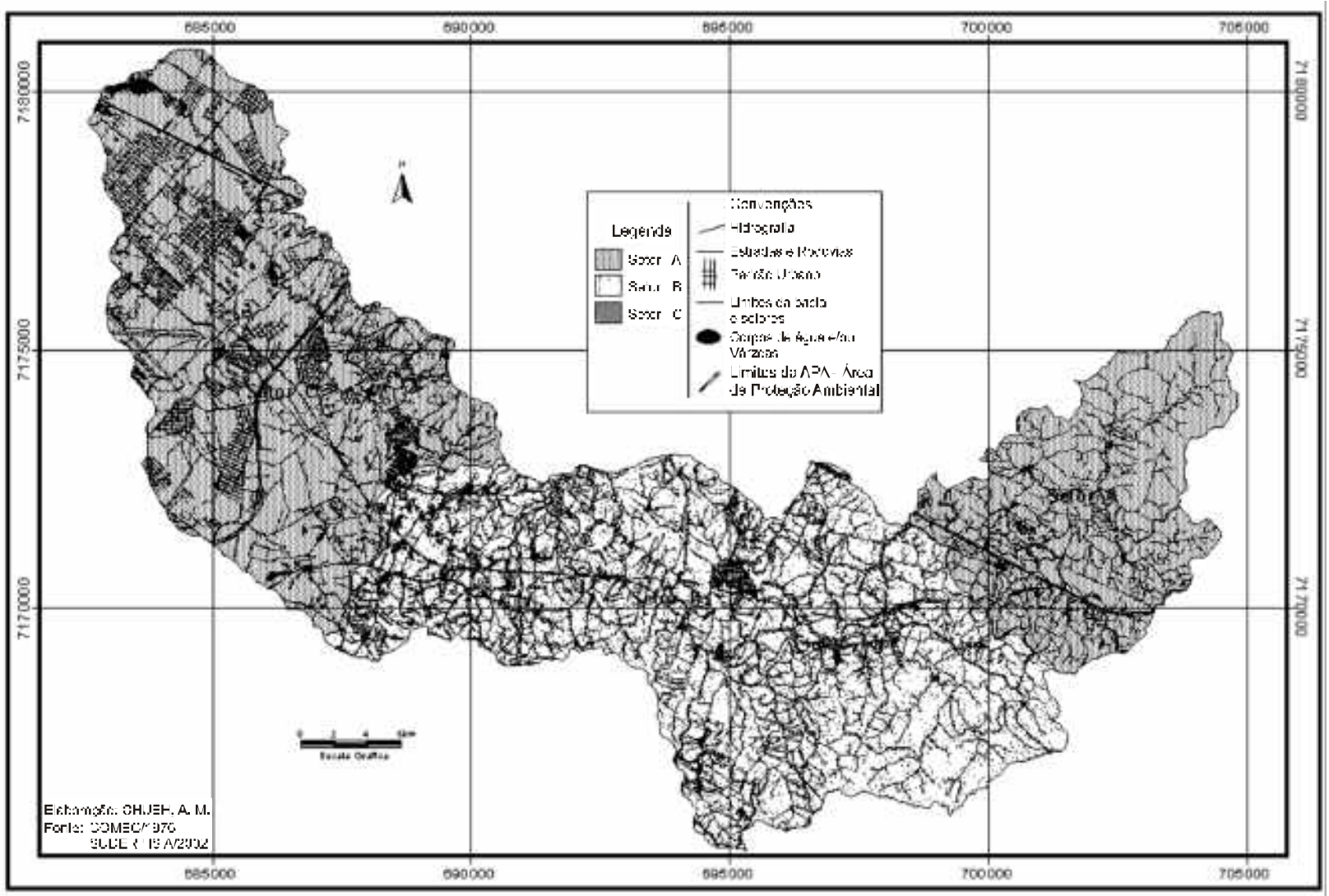

O setor $\mathrm{B}$ corresponde à parte central da bacia e é o de maior área, ou seja, ocupando $46,42 \%$ do total da bacia; possui altitudes em torno de 880 a 980 metros, com classes de declividades predominantes variando entre 0 e $20 \%$, sendo que a linha divisória entre os setores $\mathrm{B}$ e $\mathrm{C}$ corta transversalmente o rio Pequeno na cota 880 metros, seguindo o divisor de águas.

$\mathrm{O}$ setor $\mathrm{C}$, nas áreas próximas da foz do rio Pequeno, corresponde às áreas mais baixas e planas da bacia, com altitudes médias em torno de 875 metros; as altitudes máximas são em torno de 920 metros, e se localizam ao longo dos divisores de águas ao norte e ao sul do rio principal. A classe de declividade predominante é entre 0 e $8 \%$, abrangendo uma área em torno de $88 \%$ deste setor.

\section{CÁLCULO DO VALOR DO PROCESSO DE DEGRA- DAÇÃO DA BACIA}

O resultado das classificações da síntese dos parâmetros em que o mínimo é 7 (soma de todos os índices iguais a 1), representa o melhor índice do estado físico conservacionista que o setor pode apresentar. O valor máximo a ser obtido é 39 (soma de todos os índices com valores máximos), o que representa o pior estado físico que o setor pode apresentar. Com estes valores, mínimo de 7 e máximo de 39, tem-se o ângulo de inclinação da reta (Figura $03)$, para isto foi utilizada a equação da reta $y=a x+b$; $(y=3,125$ e $x=21,875)$, cujos resultados estão resumidos na Tabela 1, e representam as unidades de risco de erosão por setores na bacia.

TABELA 1 - UNIDADES DE RISCO DE EROSÃO POR SETORES DA BACIA DO RIO PEQUENO

\begin{tabular}{|c|c|}
\hline SETORES & UNIDADES DE RISCO $(0-100)$ \\
\hline A & 46,875 \\
\hline B & 46,875 \\
\hline C & 34,375 \\
\hline
\end{tabular}


CHUEH, A. M.; SANTOS, L. J. C. Análise do potencial de degradação ambiental na bacia...

FIGURA 3 - REPRESENTAÇÃO DA EQUAÇÃO DA RETA DOS VALORES DA FÓRMULA DESCRITIVA, POR UNIDADES DE RISCO DE EROSÃO DOS SET ORES DA BACIA DO RIO PEQUENO

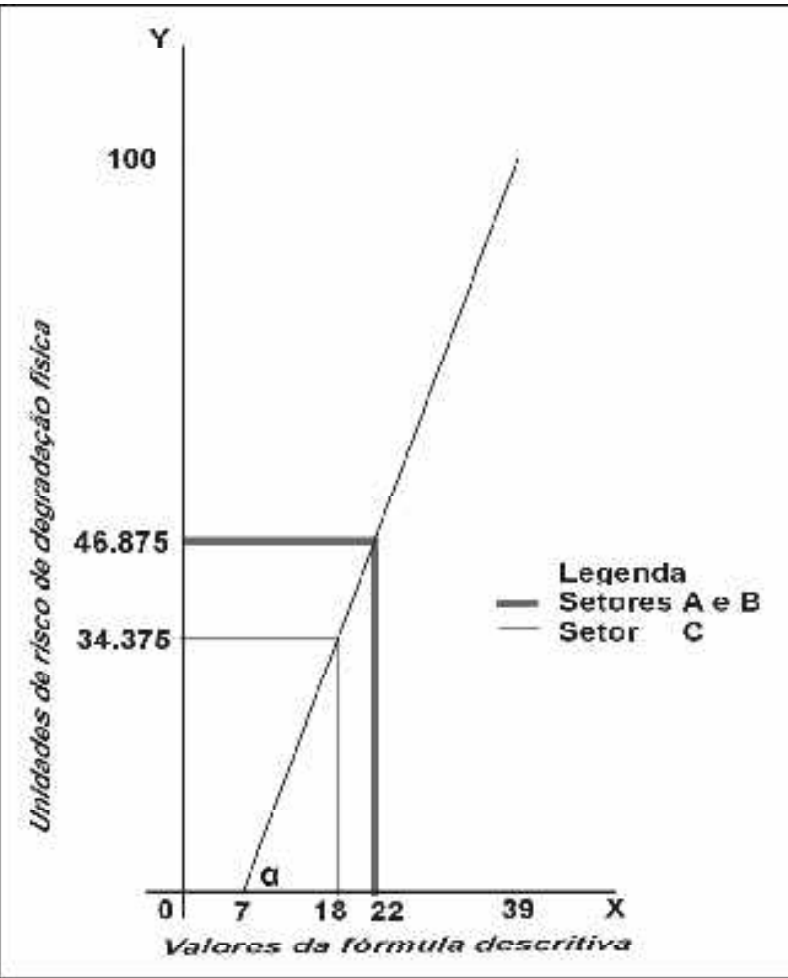

Alocando-se os valores obtidos sobre um plano cartesiano, cujo valor de cada unidade de risco de degradação física vale 3,125, tem-se a representação do ângulo de inclinação da reta demonstrada na Figura 3.

Para a representação do estado original da bacia na figura acima, admitindo-se as coordenadas $(x=7$ e y $=0$ ), a reta deveria estar paralela ao eixo das ordenadas, formando um ângulo reto com as abcissas. Desta forma, conclui-se que as condições físico-conservacionistas dos setores é inversamente proporcional ao ângulo $(\alpha)$ de inclinação da reta com o eixo das abcissas, ou seja, quanto menor o ângulo de inclinação, piores são as condições dos recursos naturais nos setores da bacia, e por sua vez, maior o risco de degradação física.

\section{AVALIAÇÃO DOS RESULTADOS OBTIDOS PELO DFC}

Os parâmetros com os respectivos índices na fórmula descritiva permitem uma análise qualitativa quanto ao índice de preservação dos recursos naturais da bacia.
A fórmula descritiva genérica que foi obtida em cada setor da bacia hidrográfica do rio Pequeno é a seguinte:

$$
E(f)=C O a+C A b+D M c+E d+P E e+D D f+B H g
$$

Sendo que:

$E(f)$ - representa as condições físicas-ambientais de conservação do setor, que é proporcional aos resultados dos parâmetros;

$\mathrm{COa}$ - grau de semelhança entre a cobertura vegetal original e o uso atual, 'a' é o índice específico do parâmetro, que varia entre 1 - altamente semelhante e 5 - nenhuma semelhança;

CAb - proteção do solo de acordo com o tipo de uso, 'b' é o índice específico do parâmetro, que varia entre 1 - máxima proteção e 7 - nenhuma proteção;

DMc - declividade média: 'c' é o índice específico do parâmetro, que varia entre 1 - plano suave a ondulado e 5 - escarpado;

Ed - erosividade da chuva: 'd' é o índice específico do parâmetro, que varia de 1 - erosão débil a 4 - erosão muito forte;

PEe - potencial erosivo dos solos: 'e' é o índice específico do parâmetro, que varia entre 1 baixa e 4 - muito alta;

DDf - densidade de drenagem: ' $g$ ' é o índice específico do parâmetro, que varia entre 1 baixa densidade e 4 - muito alta densidade;

$\mathrm{BHg}$ - balanço hídrico: ' $g$ ' é o índice específico do parâmetro, que varia entre 1 - balanço hídrico muito alto e 4 - balanço hídrico baixo.

Com base na metodologia utilizada por Beltrame (1994), e algumas adaptações, o resultado da síntese dos parâmetros dos fatores potenciais de degradação dos recursos naturais estão expressos de forma numérica por meio da fórmula descritiva final no Quadro 2.

Comparando-se os resultados dos índices dos parâmetros da fórmula descritiva dos setores, verificouse que:

a) a cobertura vegetal original (CO) do setor $\mathrm{C}$, dentre os demais, é a que apresentou menor semelhança com a atual, demonstrando que as alterações ocorridas na cobertura original foram mais intensas. Haja vista que as áreas próximas da foz do rio Pequeno estão no limite de expansão urbana da RMC de Curitiba, e também originalmente estas áreas eram cobertas por campos, onde o relevo com baixas declividades favoreceu ainda mais a sua 
CHUEH, A. M.; SANTOS, L. J. C. Análise do potencial de degradação ambiental na bacia...

QUADRO 2: SÍNTESE DOS ÍNDICES OBTIDOS EM CADA PARÂMETRO POR SETOR

\begin{tabular}{|lc|c|c|}
\hline \multicolumn{1}{|c|}{ PARÂMETRO } & SETOR A & SETOR B & SETOR C \\
\hline Cobertura vegetal original & $\mathrm{CO}$ & $\mathrm{CO}_{4}$ & $\mathrm{CO}_{5}$ \\
Erosividade da chuva & $\mathrm{E}_{5}$ & $\mathrm{E}_{2}$ & $\mathrm{E}_{2}$ \\
Declividade média & $\mathrm{DM}_{2}$ & $\mathrm{DM}_{2}$ & $\mathrm{DM}_{1}$ \\
Potencial erosivo do solo & $\mathrm{PE}_{5}$ & $\mathrm{PE}_{1}$ & $\mathrm{PE}_{2}$ \\
Cobertura vegetal atual & $\mathrm{CA}_{2}$ & $\mathrm{CA}_{3}$ & $\mathrm{CA}_{2}$ \\
Densidade de drenagem & $\mathrm{DD}_{1}$ & $\mathrm{DD}$ & $\mathrm{DD}_{2}$ \\
Balanço hídrico & $\mathrm{BH}_{2}$ & $\mathrm{BH}_{2}$ & $\mathrm{BH}_{z}$ \\
\hline SOMAToRIA DOS ínDICES & 22 & 22 & 18 \\
\hline
\end{tabular}

urbanização, que representa $16,3 \%$ da área total deste setor. Nas áreas mais a montante os campos foram tomados pelo uso de práticas agropecuárias intensivas, com $63,48 \%$ da área total do setor;

b) a cobertura vegetal atual (CA) oferece menos proteção ao solo nos setores B e C, onde podem ser observadas as maiores alterações nas coberturas originais, enquanto que o setor $A$ é o que menos sofreu alterações em sua cobertura, predominando o uso como áreas de florestas ou fases inicial ou intermediária da sucessão, principalmente pela dificuldade de acesso decorrente da natureza do relevo;

c) para a declividade média (DM) utilizou-se a base cartográfica em escala 1:10.000 e eqüidistância de cinco metros entre as curvas de nível, o que confirmou a elevada amplitude do gradiente do canal principal entre os setores A e B, apresentado no perfil longitudinal do rio principal. Também, comparando-se este índice entre os setores A, B e C, tornam-se compreensíveis as diferentes feições do relevo na bacia;

d) a erosividade da chuva (E) nos setores $A$ e $B$ apresentou o mesmo índice, em razão da influência orográfica da Serra do Mar, enquanto que no setor $\mathrm{C}$ o índice foi menor;

e) o potencial erosivo dos solos (E) apresentou-se menor no setor $C$, tendo em vista que os fatores determinantes neste parâmetro são a declividade e a suscetibilidade do solo à erosão. É neste setor que o relevo apresenta-se de plano a suave-ondulado e os tipos de solos predominantes (Latossolo, Gleissolo e Organossolo) não favorecem o desenvolvimento de processos erosivos, enquanto que os setores $A$ e $B$, respectivamente, apresentaram índices maiores do potencial erosivo dos solos, com solos mais suscetíveis à erosão, combinados com a declividade mais acentuada.

De maneira geral, a bacia hidrográfica do rio Pequeno apresentou uma cobertura vegetal com baixa semelhança com a original, com forte erosividade da chuva e potencial erosivo dos solos altos.

Os resultados obtidos propiciaram uma análise quantitativa do potencial de degradação de cada setor. Como resultados finais, os setores A e B apresentaram igual valor quanto ao risco de degradação física - 46,875 unidades de risco de degradação física (Figura 3), demonstrando que estão sob as mesmas condições em termos de conservação física do ambiente, tendo em comum os índices de erosividade da chuva (E3), densidade de drenagem (DD4) e balanço hídrico (BH2).

Estes setores apresentaram os maiores índices do potencial erosivo dos solos, respectivamente (PE5) e (PE4), com solos mais suscetíveis à erosão, combinados com a declividade mais acentuada, particularmente no setor A. No setor B, deve-se ter uma atenção especial nas medidas conservacionistas, pois o uso do solo atual mostra que há intensificação do uso agropecuário, o qual vem avançando sobre os demais tipos de uso que poderiam propiciar maior proteção ao solo.

No setor $C$, os resultados dos índices dos parâmetros demonstraram características distintas dos outros, com exceção do balanço hídrico $(\mathrm{BH})$, nenhum outro foi semelhante aos demais setores. Embora com índice menor - 34,375 unidades de riscos de erosão, foi o que teve alterações mais significativas na sua cobertura vegetal original, a qual foi substituída pelos tipos de usos agropecuários e por áreas urbanas, o que 
CHUEH, A. M.; SANTOS, L. J. C. Análise do potencial de degradação ambiental na bacia...

pode intensificar os impactos ambientais negativos, devendo estas alterações serem consideradas no planejamento e nas medidas conservacionistas a serem adotadas.

\section{CONSIDERAÇÕES FINAIS}

A utilização do DFC - Diagnóstico FísicoConservacionista se mostrou eficiente na avaliação da degradação física da bacia hidrográfica em estudo. No entanto, o aperfeiçoamento e o incremento de soluções na obtenção dos índices dos parâmetros da fórmula proposta é conseqüência de exercícios metodológicos, proporcionados pelos experimentos acadêmicos ou pela utilização da metodologia como suporte no planejamento de bacias hidrográficas. É importante lembrar que os resultados deste diagnóstico devem estar integrados a outros diagnósticos específicos, tais como: condições socioeconômicas da população, a qualidade da água, análise das características da fauna, entre outras, para que se possa determinar não só os fatores naturais, mas também os fatores socioambientais que possibilitam a degradação da bacia hidrográfica, isto resultará no Diagnóstico Integral de Bacias Hidrográficas (DIBH).

Contudo, para o desenvolvimento desta pesquisa, foi necessário adequar a proposta de Beltrame (1990) às condições próprias da área de estudo. Tanto pelas peculiaridades da mesma, quanto pela aquisição dos dados que subsidiassem a obtenção dos índices que compõem cada parâmetro da fórmula descritiva final.

O conflito entre a expansão do uso do solo, potencializada pelas práticas que geram impactos ambientais, e a necessidade de manutenção das áreas desta bacia como área de preservação ambiental, mostra a importância em ser efetivado um plano de ação que contemple estas contradições. Haja vista que as alterações na superfície de uma área podem levar o ambiente ao desequilíbrio, e por sua vez à degradação

\section{REFERÊNCIAS}

AMARAL, S. B. do. Aspectos da relação entre uso - ocupação do solo e qualidade da água na bacia hidrográfica do Rio Pequeno - São José dos Pinhais/Pr. Curitiba, 2002. 115 p. Dissertação (Mestrado em Gestão Ambiental) - Departamento de Geografia, Setor de Ciências da Terra, Universidade Federal do Paraná.

BELTRAME, A. V. Diagnóstico do meio físico de bacias hidrográficas: modelo e aplicação. Florianópolis: UFSC, 1994. de seus recursos naturais, especialmente do solo e dos recursos hídricos.

As transformações decorrentes do uso do solo da bacia do rio Pequeno foram se intensificando, sobretudo nas três últimas décadas, principalmente no baixo curso, com a implantação de áreas urbanizadas, as quais estão localizadas especialmente no setor $\mathrm{C} \mathrm{e}$ consolidadas de forma irreversível. Embora as características físicas deste setor estejam suportando as ações antrópicas que podem acelerar os processos erosivos, e também, diante da possibilidade de contaminação do solo e dos canais fluviais com resíduos de esgotos doméstico e/ou industrial decorrentes das áreas urbanizadas, é necessário dotá-las de infraestrutura e desenvolver mecanismos de controle do aumento do escoamento superficial, face a impermeabilização do solo.

Outra atividade que pode proporcionar alterações que produzem efeitos degradantes ao ambiente como um todo, e diretamente ao solo, é a agropecuária, sendo relevantes as práticas agrícolas. Este tipo de uso está presente em toda extensão da bacia, mas com maior intensidade nos setores $B$ e $C$, onde normalmente praticam-se culturas de ciclos curtos ou temporários, com ênfase nas hortaliças, o que demanda maiores cuidados nas práticas conservacionistas, tanto pela degradação física, quanto pela contaminação química do solo, comprometendo-se, assim, também os cursos de água.

As características físicas das áreas localizadas no alto curso da bacia e em parte do médio curso, onde foram delimitados os setores A e B, potencialmente são as mais vulneráveis à degradação do solo se houver alteração na cobertura vegetal, em razão da declividade acentuada do relevo. É necessário, portanto, preservar as áreas com florestas e favorecer a recuperação das áreas que tenham sofrido alterações nas suas características originais. 
CHUEH, A. M.; SANTOS, L. J. C. Análise do potencial de degradação ambiental na bacia...

- Departamento de Geografia, Setor de Ciências da Terra, Universidade Federal do Paraná.

CHUEH, A. M. Legislação ambiental e meio ambiente na bacia hidrográfica do rio Pequeno: situação atual e possibilidades. Curitiba, 2000. Monografia (Conclusão de Curso) Departamento de Geografia, Setor de Ciências da Terra, UFPR.

COMEC. Coordenação da Região Metropolitana de Curitiba. Relatório ambiental da Região Metropolitana de Curitiba. Curitiba, 1997.

EMBRAPA. Mapa de solos do Estado do Paraná. Escala 1:600.000. Curitiba, 1974.

Sistema brasileiro de classificação de solos. Brasília, 1999. $412 \mathrm{p}$

FERRETTI, E. R. Diagnóstico físico conservacionista - DFC da bacia do rio Marrecas - sudoeste do Paraná. Curitiba, 1998. 194 p. Dissertação (Mestrado) - Universidade Federal do Paraná.

GUIMARÃES, J. L. B. A relação entre a ocupação do solo e o comportamento hídrico na bacia hidrográfica do rio Pequeno - São José dos Pinhais - PR. Curitiba, 2000. Dissertação (Mestrado em Conservação da Natureza) - Setor de Agrárias, Universidade Federal do Paraná.

KLEIN, R. M.; HATSCHBACH, G. Fitofisionomia e notas sobre a vegetação para acompanhar a planta fitogeográfica do município de Curitiba e arredores (Paraná). Boletim da Universidade do Paraná, Curitiba, Instituto de Geologia, n.4,1962.

PARANÁ, Secretaria de Estado do Meio Ambiente e Recursos Hídricos. Mapeamento da Floresta Atlântica do Estado do Paraná: cartilha de apoio à interpretação das cartas de vegetação. Curitiba, 2002.

PUNDEK, M. Utilização prática da equação de perdas de solo para as condições de Santa Catarina. In: SANTA CATARINA.
Secretaria de Estado da Agricultura e Abastecimento. Manual de uso, manejo e conservação: projeto de recuperação, conservação e manejo dos recursos naturais em microbacias hidrográficas. 2. ed. Florianópolis: Epagri, 1994. p. 99-131.

ROCHA, A. L. Caracterização ambiental, hidrogeológica e geoquímica dos depósitos aluvionares da bacia hidrográfica do rio Pequeno - Região Metropolitana de Curitiba - PR. Curitiba, 1996. 157 p. Dissertação (Mestrado em Geologia Ambiental), Universidade Federal do Paraná.

RODERJAN, C. V. et al. As unidades fitogeográficas do Estado do Paraná, Brasil. Revista Ciência e Ambiente - Fitogeografia do Sul da América, Santa Maria - RS, Universidade Federal de Santa Maria, n. 24, p. 75 -92, 2002.

RUFINO, R. L. et al. Determinação do potencial erosivo da chuva do Estado do Paraná: terceira aproximação. Revista Brasileira Ci., Campinas, v. 17, 1993, p. 439 - 444.

SANTOS, C. I. S. dos. Avaliação de perdas de solo por erosão hídrica na Bacia Hidrográfica do Rio Pequeno - São José dos Pinhais/Pr. Curitiba, 2002. 69 p. Monografia (Conclusão de Curso) - Departamento de Geografia, Setor de Ciências da Terra, Universidade Federal do Paraná.

SANTOS, I. dos Modelagem geobiohidrológica como ferramenta no planejamento Ambiental: Estudo da bacia hidrográfica do rio Pequeno - São José dos Pinhais/Pr. Curitiba, 2001. 92 p. Dissertação (Mestrado em Ciência do Solo) - Setor de Ciências Agrárias, Universidade Federal do Paraná.

SANTOS, M. Metamorfose do espaço habitado. 4. ed. São Paulo: Hucitec,1996.

TONETTI, J. B. Mapa integrado de ambientes com instabilidade potencial na bacia do rio Pequeno - São José dos Pinhais. Curitiba, 1993. Monografia (Especialização) Departamento de Geologia, Universidade Federal do Paraná. 